\title{
Weighted Additive Fuzzy Goal Programming Approach to Aggregate Production Planning
}

\author{
Mohammed. Mekidiche \\ Faculty of Economics and Commerce, University of Tlemcen, -Maghnia Annex -Algeria \\ E-mail: mkidiche@yahoo.fr \\ Mostefa Belmokaddem \\ Faculty of Economics and Commerce, University of Tlemcen, Algeria \\ E-mail: belmo_mus@yahoo.fr \\ Zakaria Djemmaa \\ Faculty of Economics and Commerce, University of Tlemcen, Algeria \\ E-mail: djemmaa_z@yahoo.fr
}

\begin{abstract}
This study presents a new formulation of Weighted Additive fuzzy goal programming model developed by Yaghoobi and Tamiz [21]. and Yaghoobi et al [22] for aggregate production planning (WAFGPAPP), The proposed formulation attempts to minimize total production and work force costs, carrying inventory costs and rates of changes in Work force. A real-world industrial case study demonstrates applicability of proposed model to practical APP decision problems. LINGO computer package has been used to solve final crisp linear programming problem package and getting optimal production plan.
\end{abstract}

Index Terms - Aggregate Production Planning, Weighted Additive Fuzzy Goals Programming, Membership Function

\section{Introduction}

Aggregate production planning (APP) deals with matching supply and demand of forecasted and fluctuated customer's orders over the medium time range, up to approximately 12 months into the future. The problem of aggregate production planning is concerned with management's response to fluctuations in the demand pattern. Specifically, haw can the productive, man power, and goods resources best be utilized in the face of changing demands in order to minimize the total cost of operations over a given planning horizon.

In responding to changing demands, manage ment can utilize the following strategies:

- Adjust the work force through hiring and firing.

- Adjust the production rate through overtime and under-time.
- Absorb demand fluctuation rate through inventory back logging or allowing lost sales.

- The production rate may be kept on a constant level and the fluctuations in demand met by altering the level of subcontracting.

Clearly, each of the above pure strategies implies a set of cost which may be both direct and opportunity. Changing the work force implies costs associated with hiring and layoff. Production rate changes entail costs of overtime and idle resource. Excess inventories require capital investment as well as direct costs while shortages imply lost revenue and customer goodwill.

Any combination of these preceding strategies is course also possible. The problem of the APP is to select the strategy with least cost to the firm. This problem has been under an extensive discussion and several alternative methods for finding an optimal solution have been suggested in the literature.

The term "aggregate" implies that the planning is done for a few aggregate product categories. The purposes of APP are (1) to set up overall production levels for each product category to meet the fluctuating or uncertain demands in the near future; (2) to set up decisions and polices on the issues of hiring, layoff, overtime, backorder, subcontracting, and inventory level, which means that the APP will determine the appropriate Resources to be used as well.

When using any of the APP models, it is often assumed that the goals and the model inputs (resources and demands) are deterministic/crisp. In practice, demands, resources and costs are usually imprecise/fuzzy. The current APP model represents the information in a fuzzy environment where the objective function and the parameters are not completely defined and cannot be accurately measured. The best compromise APP will balance the cost of building and holding inventory against the cost of adjusting activity 
levels to meet the fluctuations in demands. The forecasted demand in a particular period could either be satisfied or backordered. However, the backorder must be fulfilled within the next period.

This research paper has IX sections. In section I is introduction and the definition of the problem of APP. In section II, will address the literature review of APP. In section III dealt a Fuzzy goal programming (FGP).In section IV we study the types of membership functions, The section $\mathrm{V}$ we dealt with the Weighted additive fuzzy goal programming (WAFGP), proposed by Yaghoobi et al [22].in the Section VI we explained the how to formulate the problem of APP as a multiobjective problem. The section VII we have using WAFGP to formulate the problem of APP, a real-world industrial case study demonstrates applicability of proposed model in section VIII, Finally conclusion is presented in Section IX.

\section{Literature Review}

Since Holt, Modigliani, and Simon [10] proposed the HMMS rule in 1955, researchers have developed numerous models to help to solve the APP problem, each with their own pros and cons. According to Saad [15], al traditional models of APP problems may be classified into six categories - (1) linear programming (LP) [5, 16], (2) linear decision rule (LDR) [10], (3) transportation method [2], (4) management coefficient approach [3], (5) search decision rule (SDR) [18], and (6) simulation [11]. When using any of the APP models, the goals and model inputs (resources and demand) are generally assumed to be deterministic/crisp and only APP problems with the single objective of minimizing cost over the planning period can be solved. The best APP balances the cost of building and taking inventory with the cost of the adjusting activity levels to meet fluctuating demand.

In practice, the input data in the problem of APP and also data of demand, resources and cost, as well as the objective function are frequently imprecise/fuzzy because some information is incomplete or unobtainable. Traditional mathematical programming techniques clearly cannot solve all fuzzy programming problems. In 1976, Zimmermann [24] first introduced fuzzy set theory into conventionalLP problems.

Many aspects of the APP problem and the solution procedures employed to solve APP problems lend themselves to the fuzzy set theory approach. Fuzzy APP allows the vagueness that exists in the determining forecasted demand and the parameters associated with carrying charges, backorder costs, and lost sales to be included in the problem formulation. Fuzzy linguistic "if-then" statements may be incorporated into the APP decision rules as means for introducing the judgment and past experience of the decision maker into the problem. In this fashion, fuzzy set theory increases the model realism and enhances the implementation of APP models in industry. The usefulness of fuzzy set theory also extends to multiple objective APP models where additional imprecision due to conflicting goals may enter into the problem.

Gen et al [7]. Present a fuzzy multiple objective aggregate planning models. The model is formulated as a fuzzy multiple objective programming model with objective function coefficients, technological coefficients and resource right-hand side values, represented by triangular fuzzy numbers. A transformation procedure is presented to transform the fuzzy multiple objective APP model into a crisp model. The transformation procedure and computational algorithm are demonstrated for a numerical example involving a six-period planning horizon. Multiple objectives of minimizing total production costs, inventory and backorder costs, and changes in the work force level were used.

Tang et al. [17] focus on a novel approach to modeling multi-product APP problems with fuzzy demands and fuzzy capacities, considering that the demand requirements are fuzzy demand in each period during the planning horizon, The objective of the problem considered is to minimize the total costs of quadratic production costs and linear inventory holding costs. By means of formulation of fuzzy demand, fuzzy addition and fuzzy equation, the production inventory balance equation in single stage and dynamic balance equation are formulated as soft equations in terms of a degree of truth, and interpreted as the levels of satisfaction with production and inventory plan in meeting market demands. As a result, the multi-product APP problem with fuzzy demands and fuzzy capacities can be modeled into a fuzzy quadratic programming with fuzzy objective and fuzzy constraints.

Wang and Fang [19] present a novel fuzzy linear programming method for solving the APP problem with multiple objectives where the product price, unit cost to subcontract, work force level, production capacity and market demands are fuzzy in nature. An interactive solution procedure is developed to provide a compromise solution.

Wang and Liang [20] develop a fuzzy multi-objective linear programming model for solving the multi-product APP decision problem in a fuzzy environment. The proposed model attempts to minimize total production costs, carrying and backordering costs and rates of changes in labor levels considering inventory level, labor levels, capacity, warehouse space and the time value of money.

Abouzar Jamalnia and Mohammad Ali Soukhakian [1] developed a hybrid (including qualitative and quantitative objectives) fuzzy multi objective nonlinear programming model with different goal priorities for solving APP problem in a fuzzy environment. the proposed model tries to minimize total production costs, carrying and back ordering costs and costs of changes in workforce level (quantitative objectives) and maximize 
total customer satisfaction (qualitative objective) with regarding the inventory level, demand, labor level, machines capacity and warehouse space.

This study presents an new formu lation of APP based A Weighted additive fuzzy goal programming (WAFGP) model developed by Yaghoobi and Tamiz [21] and Yaghoobi et al [22] and its application in the national firm of iron manufactures non- metallic and useful substances for solving the problems of the APP. The proposed model minimizes total production and work force costs, cost of inventory and minimize of degree of change in Work force.

\section{Fuzzy Goal Programming}

A useful tool for dealing with imprecision is fuzzy set theory [23]. An objective with an imprecise aspiration level can be treated as a fuzzy goal. In itially, Narasimhan [14] incorporated fuzzy set theory in goal programming (GP) in 1980 and presented a fuzzy goal programming FGP model [14]. Hannan simplified the Narasimhan method to an equivalent simple linear programming in 1981 [9]. These pioneering works led to extensive research in the use and application of FGP to real life problems.

To solve FGP problems various models based on different approaches have been proposed. A survey and classification of FGP models has been presented by Chanas and Kuchta [6]. There are three types of fuzzy goals which are the most common. The following FGP model contains these fuzzy goals.

$$
\begin{aligned}
\text { OPT }(A X)_{i} \underset{\approx}{\leq} b_{i} \quad i=1, \ldots, i_{O} \\
(A X)_{i} \underset{\approx}{\geq} b_{i} \quad i=i_{O}+1, \ldots, j_{0} \\
(A X)_{i} \cong \quad i=j_{O}+1, \ldots, K \\
X \in C_{S}
\end{aligned}
$$

Where OPT means finding an optimal decision $X$ such that all fuzzy goals are satisfied, $A X)_{i}=$ $\sum_{j=1}^{n} a_{i j} x_{j} \quad i=1, \ldots, k, b_{i}$ is the aspiration level for $i . t h$ goal, and the symbol $\cong$ is a fuzzifier representing the imprecise fashion in which the goals are stated

\section{Membership Function}

Narasimhan [14] and Hannan [8, 9] were the first to give a FGP formulation by using the concept of the membership functions. These functions are defined on the interval $[0,1]$. So, the membership function for the $i-t h$ goal has a value of 1 when this goal is attained and the decision makers are totally satisfied; otherwise the membership function assumes a value between 0 and 1 .

Linear membership functions are used in literature and practice more than other types of membership

\begin{tabular}{|c|c|}
\hline Membership function & Analytical definition \\
\hline$\underset{b_{i} \quad b_{i}+\Delta_{i R}}{\longrightarrow}(A X)_{i}$ & $\mu_{i}(A X)_{i}= \begin{cases}1 & \text { if }(A X)_{i} \leq b_{i} \\
1-\frac{(A X)_{i}-b_{i}}{\Delta_{i R}} & \text { if } \quad b_{i} \leq(A X)_{i} \leq b_{i}+\Delta_{i R} \quad i=1, . ., i_{0}(1) \\
0 & \text { if } . .(A X)_{i} \geq b_{i}+\Delta_{i R}\end{cases}$ \\
\hline & Type 1 \\
\hline$\underset{b_{i}-\Delta_{i L}}{\stackrel{b_{i}}{\vdots}}$ & $\mu_{i}(A X)_{i}= \begin{cases}1 & \text { if }(A X)_{i} \geq b_{i} \\
1-\frac{b_{i}-(A X)_{i}}{\Delta_{i L}} & \text { if } b_{i}-\Delta_{i L} \leq(A X)_{i} \leq b_{i} \quad i=i_{0}+1, \ldots, j_{0} \quad(2) \\
0 & \text { if }(A X)_{i} \leq b_{i}-\Delta_{i L}\end{cases}$ \\
\hline \multicolumn{2}{|r|}{ Type 2} \\
\hline
\end{tabular}
functions. For the above four types of fuzzy goals linear membership functions are defined and depicted as follows ( Fig. 1): 


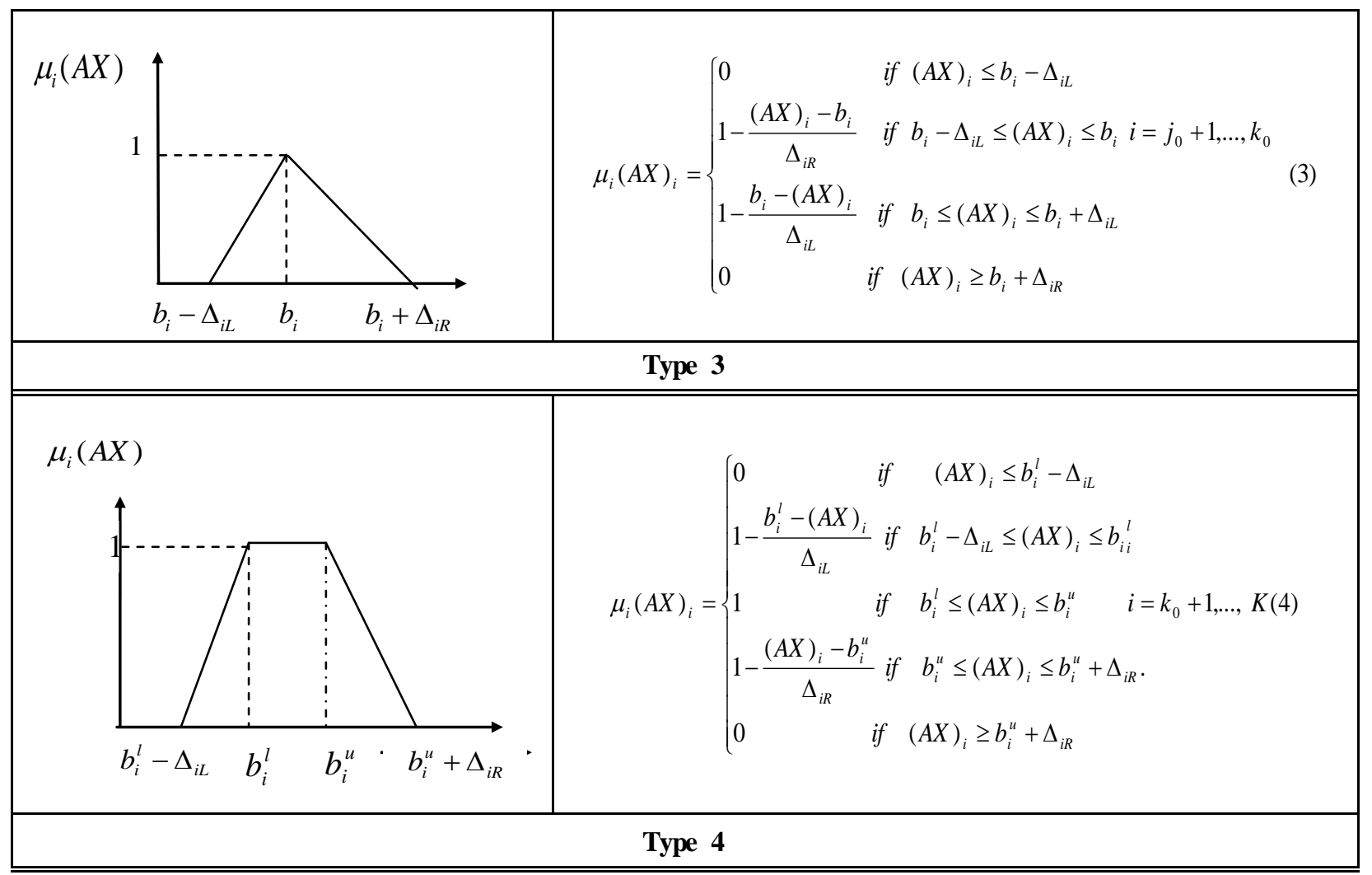

Fig. 1: linear membership function and Analytical definition

Where $\Delta_{i R}\left(\right.$ or $\left.\Delta_{i L}\right)$ is the quantity of a tolerance for the case of fuzzy goal, $(A X)_{i}=$ $\sum_{j=1}^{n} a_{i j} x_{j} . i=1, \ldots, k, b_{i}$ is the aspiration level for $i . t h$ goal, $C_{s}$ is an optional set of hard constraints as found in linear programming (LP).

\section{A Weighted Additive Fuzzy Goal Programming (WAFGP)}

Yaghoobi et al [22] has been proposed other approach for solving FGP problems with unequal weights can be formulated as a single linear programming problem with the concept of tolerances, The attempted to extend Kim and Whang [12] model and Yagoobi and Tamiz [21] by introducing an LP model that is able all types of memberships functions (type1-type4) their model can be formulated as follow: $\min z=\sum_{i=1}^{i_{0}} w_{i} \frac{\delta_{i}^{+}}{\Delta_{i R}}+\sum_{i=i_{0}+1}^{j_{o}} w_{i} \frac{\delta_{i}^{-}}{\Delta_{i L}}+\sum_{i=j_{o}+1}^{K} w_{i}\left(\frac{\delta_{i}^{-}}{\Delta_{i L}}+\frac{\delta_{i}^{+}}{\Delta_{i R}}\right)$

subject to:

$$
\begin{array}{lc}
(A X)_{i}-\delta_{i}^{+} \leq b_{i} & i=1, \ldots, i_{o} \\
\mu_{i}+\frac{\delta_{i}^{+}}{\Delta_{i R}}=1 & i=1, \ldots, i_{o} \\
(A X)_{i}+\delta_{i}^{-} \geq b_{i} & i=i_{0}+1, \ldots, j_{0} \\
\mu_{i}+\frac{\delta_{i}^{-}}{\Delta_{i L}}=1 & i=i_{0}+1, \ldots, j_{0} \\
(A X)_{i}+\delta_{i}^{-}-\delta_{i}^{+}=b_{i} & i=j_{o}+1, \ldots, k_{0} \\
\mu_{i}+\frac{\delta_{i}^{-}}{\Delta_{i L}}+\frac{\delta_{i}^{+}}{\Delta_{i R}}=1 & i=j_{o}+1, \ldots, K \\
(A X)_{i}+\delta_{i}^{-}-\delta_{i}^{+}=b_{i} & i=j_{o}+1, \ldots, K \\
(A X)_{i}-\delta_{i}^{+} \leq b_{i}^{u} & i=k_{0}+1, \ldots, K \\
(A X)_{i}+\delta_{i}^{-} \geq b_{i}^{l} & i=k_{0}+1, \ldots, K \\
\mu_{i}, \delta_{i}^{-}, \delta_{i}^{+} \geq 0 & i=1, \ldots, K \\
X \in C_{s} &
\end{array}
$$

Where $C_{s}$ an optional set of hard constraints as is found in linear programming (LP) $\mu_{i}$ is degree of membership function for ith goal.

The advantages of new model are: 
- the WAFGP developed by Yaghoobi et al [22] can de utilized for these types of membership functions

- the new formulation determines the degree of membership function for every variables

- The optimal solution of new model is equal to the degree of membership function for ith fuzzy goal.

\section{Multi-Objective Programming (MOP) Model To APP}

\subsection{Parameters and constants definition}

$v_{i t}$ : Production cost for product $i$ in period $t$ excluding labour cost in period $t$ (Unit).

$c_{i t}$ : Inventory carrying cost for product $i$ between period $t$ and $t+1$.

$r_{t}$ : Regular time work force cost per employee hour in period $t$.

$d_{i t}$ : Forecasted demand for product $i$ in period $t$. (Units).

$K_{i t}$ : Quantity to produce one worker in regular time for product $i$ in period $t$.

$I_{o i}:$ Initial inventory level for product $i$.(units)

$T$ : Horizon of planning.

$N$ : Total number of products

$P_{i t}$ : Quantity of $i$ product to the period $t$.

$I_{i t}$ : Inventory level for product $i$ in period $\boldsymbol{t}$ (units)

$H_{t}$ : Worker hired in period $\boldsymbol{t}$ (man).

$F_{t}$ : Workers lay off in period $t(\operatorname{man})$.

$I_{i t . M i n}:$ Minimum inventory level available for product $i$ in period $t$ (units).

$W_{t}$ : Total number of work force level in period $t$ (man).

$W_{M i n}$ : The minimum work force level (man) available in period $t$.

$W_{\text {Max }}$ : The maximum work force level (man) available in period $t$.

\subsection{Objective functions}

Masud and Hwang [13] specified three objective functions to minimize total production costs, carrying and backordering costs, and rates of change in labour levels. In this study, we propose a model will be using two strategies where they are available in the national firm of iron manufactures non- metallic and useful substances. In their multi-product APP decision model, the three objectives to the APP model can be formulated as follows:

- Minimize total production costs

Min.. $Z_{1} \cong \sum_{i=1}^{N} \sum_{t=1}^{T}\left(v_{i t} P_{i t}\right)+\sum_{t=1}^{T}\left(r_{t} W_{t}+h_{t} H_{t}+f_{t} F_{t}\right)$

The production costs include: regular time production, overtime, carrying inventory, specifies the costs of change in Work force levels, including the costs of hiring and layoff workers.

- Minimize carrying costs

$$
\operatorname{Min..} Z_{2} \cong \sum_{t=1}^{T}\left(c_{i t} I_{i t}\right) \text {. }
$$

- Minimize changes in labour levels

$$
\operatorname{Min.} . Z_{3} \cong \sum_{t=1}^{T}\left(H_{t}+F_{t}\right)
$$

Where the symbol $\cong$ is the fuzzified version of $=$ and refers to the fuzzification of the aspiration levels.

The objective functions of the APP model, in this study assume that the DM has such imprecise goals as the objective functions should be essentially equal to some value. These conflicting goals are required to be simultaneously optimized by the DM in the framework of fuzzy aspiration levels.

\subsection{Constraints}

- The inventory level constraints :

$$
\begin{aligned}
& P_{i t}+I_{i, t-1}-I_{i t}=d_{i t} \\
& I_{i t} \geq I_{i t . M i n}
\end{aligned}
$$

- Constraints on labour levels:

$$
\begin{aligned}
& W_{t}-W_{t-1}-H_{t}+F_{t}=0 \\
& W_{\text {Min }} \leq W_{t} \leq W_{\text {Max }}
\end{aligned}
$$

- Constraints on labour capacity in regular and overtime:

$$
P_{i t}-K_{i t} * W_{t} \leq 0
$$

- Non-negativity constraints on decision variables:

$$
P_{i t}, I_{i t}, W_{t}, H_{t}, F_{t} \geq 0
$$




\section{WAFGP Model for APP (WAFGP-APP)}

We will use the method that was developed by Yaghoobi et al, [22] for formulated the APP problem in the fuzzy gaols, the complete WAFGP-APP model can be formulated as follows.

$\operatorname{Min} Z_{4}=\sum_{i=1}^{3} w_{i} \frac{\delta_{i}^{+}}{\Delta_{I R}}$

$S T$ :

$Z_{1}-\delta_{i}^{+} \leq b_{1} \quad$ (Minimize total production $\cos t s$ )

$Z_{2}-\delta_{i}^{+} \leq b_{2} \quad$ (Minimize carying $\cos t s$ )

$Z_{3}-\delta_{i}^{+} \leq b_{3} \quad$ (Minimize changes in labor levels)

$X_{i t}+I_{i, t-1}-I_{i t}=d_{i t}$

$I_{i t} \geq I_{i t . M i n}$

$W_{t}-W_{t-1}-H_{t}+F_{t}=0$

$W_{\text {Min }} \leq W_{t} \leq W_{\text {Max }}$

$P_{i t}-K_{i t} * W_{t} \leq 0$

$\mu_{i}+\frac{1}{\Delta_{I R}} \leq 1$

$P_{i t}, I_{i t}, W_{t}, H_{t}, F_{t}, \delta_{i}^{+} \geq 0$

\section{Model Implementation}

\subsection{An industrial case study and data description}

In this section, as a real-world industrial case a data set provided by the national firm of iron manufactures non- metallic and useful substances (BENTAL) in Algeria, This company manufactures three types of products which are important, and one of the raw materials used in many industries with: Bentonite (BEN), Carbonate of calcium (CAL), Discoloring (TD), The Firm operates 175 workers, and the system of work in the Firm is a continuous production $(8 \times 3$ hours $)$ for all days of the week except Thursday hailed the work is only a half-day and Friday, which is rest day, and production management composed in 68 worker divide in 3 groups.

The individual firm in the production of mineral products mentioned above, the demand for their products makes is large, which may cause problems in the productive capacity of this firm.

Therefore, fluctuations in demand on the level and volatility of productive capacity, calls for the Firm in an attempt to develop a plan of production, trying to cope with the impact that fluctuations in demand due to seasonal changes, Table 1 summarizes the basic data gathered from the firm, The proposed model implementation in the company has the following conditions:

1. There is a six period planning horizon.

2. A three product situation is considered.

3. The initial inventory in period 1 is $I_{10}=1857$ Tons of BEN, $I_{20}=1029$ Tons of TD and $I_{30}=1860$ Tons of CAL.

4. Minimu m inventory must be maintained during the period $t$ of product $i$ is 500.Tons

5. The costs associated with hiring and layoff; according to estimations of human resource management department per man are respectively 5178DA/man and $4155 \mathrm{DA} / \mathrm{man}$.

6. The cost of one worker in the production of three products during the $t$ period is $r_{t}=2694.706 . D A / m a n$

7. The minimum work force level (man) available in each period is $W_{\text {Min }}=55$ worker.

8. The maximum work force level available in each period is $W_{\text {Max }}=68$ worker.

9. The initial worker level is $\left(W_{0}=68\right)$.

10. The Maximu m capacity of storage in 3 products in the firms is 6000 Tons.

11. The membership's functions related to each objective, and then we will define the type of membership's functions. The details of the type of memberships function of is as follow:

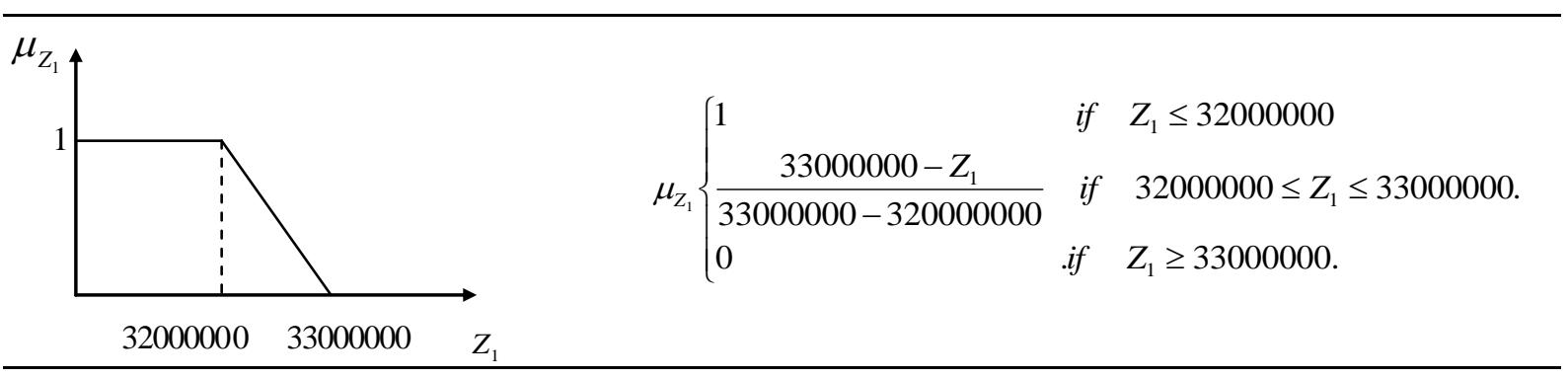

Fig. 4: Membership function of $Z_{1}$ (Minimize total production costs) 


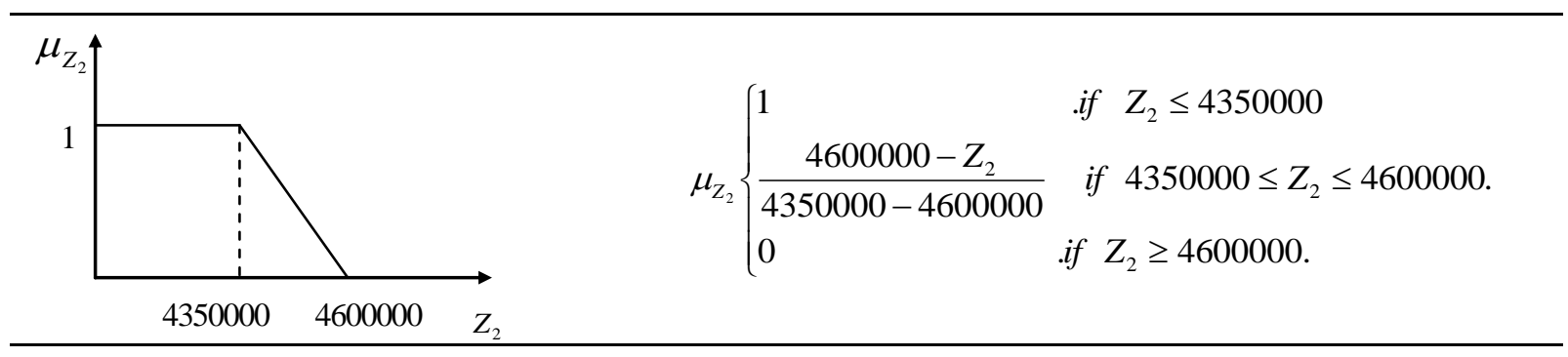

Fig. 5: Membership function of $Z_{2}$ (Minimize carrying costs)

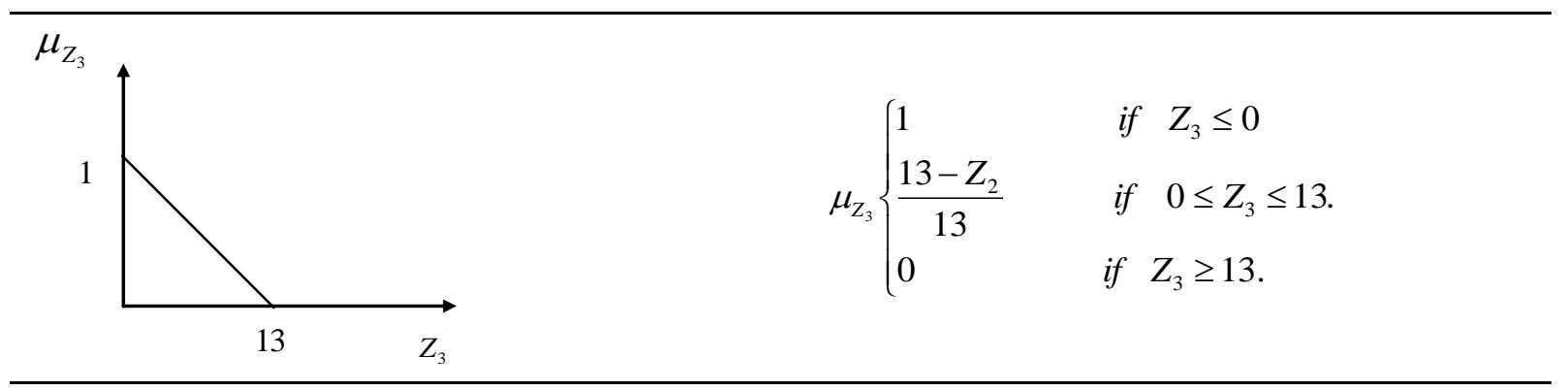

Fig. 6: Membership function of $Z_{3}$ ( Minimize changes in labour levels)

Table 1: The basic data provided by Bental firm (in units of Algeria dinar DA ...1\$ $\cong 90 \mathrm{DA}$ )

\begin{tabular}{|c|l|l|l|l|l|}
\hline Product & Period & \multicolumn{1}{|c|}{$d_{i t}$} & \multicolumn{1}{|c|}{$c_{i t}$} & $K_{i t}$ \\
\hline & 1 & 1177.225 & 3293.493 & 208.796 & 17.794 \\
& 2 & 923.021 & 3293.493 & 208.796 & 15.367 \\
BEN $\left(P_{1 t}\right)$ & 3 & 883.342 & 3293.493 & 208.796 & 18.602 \\
& 4 & 1071.99 & 3293.493 & 208.796 & 16.985 \\
& 5 & 1379.269 & 3293.493 & 208.796 & 17.794 \\
& 6 & 1315.222 & 3293.493 & 208.796 & 17.794 \\
\hline \multirow{3}{*}{ TD $\left(P_{2 t}\right)$} & 1 & 128.620 & 21646.608 & 848.721 & 3.883 \\
& 2 & 163.777 & 21646.608 & 848.721 & 3.353 \\
& 4 & 164.617 & 21646.608 & 848.721 & 4.059 \\
& 5 & 166.005 & 21646.608 & 848.721 & 3.706 \\
& 6 & 193.317 & 21646.608 & 848.721 & 3.883 \\
& 1 & 1164.191 & 1296.109 & 848.721 & 3.883 \\
\hline & 2 & 463.447 & 1296.109 & 139.149 & 14.558 \\
& 3 & 659.034 & 1296.109 & 139.149 & 12.573 \\
& 4 & 425.240 & 1296.109 & 139.149 & 15.220 \\
& 5 & 78.967 & 1296.109 & 139.149 & 13.897 \\
& 6 & 478.221 & 1296.109 & 139.149 & 14.558 \\
& & & & 14.149 & 14.558 \\
\hline
\end{tabular}

\subsection{Formulations the WAFGP-APP}

Based on the above information and using a model developing by Yaghoobi et al [22] the fuzzy goal programming formulation in this study as follows:

$\operatorname{Min} Z_{5}=\frac{\delta_{1}^{+}}{1000000}+\frac{\delta_{2}^{+}}{250000}+\frac{\delta_{3}^{+}}{13}$
Subject to:

$$
\begin{aligned}
& Z_{1}-\delta_{1}^{+} \leq 32000000 \\
& Z_{2}-\delta_{2}^{+} \leq 4350000 \\
& Z_{3}-\delta_{3}^{+} \leq 0
\end{aligned}
$$




$$
\begin{aligned}
& P_{i t}-K_{i t} \times W_{t} \leq 0 \\
& P_{i t}+I_{i, t-1}-I_{i t}=d_{i t} \\
& W_{t}-W_{t-1}-H_{t}+F_{t}=0 \\
& W_{M i n} \leq W_{t} \leq W_{\text {Max }} \\
& \sum_{i=1}^{3} I_{i t} \leq 6000 \\
& I_{i t} \geq 500 \\
& I_{10}=1856.25 \\
& I_{20}=1029 \\
& I_{30}=1860 \\
& W_{0}=68 \\
& \mu_{1}+\frac{\delta_{1}^{+}}{1000000} \leq 1 \\
& \mu_{2}+\frac{\delta_{2}^{+}}{250000} \leq 1 \\
& \mu_{3}+\frac{\delta_{3}^{+}}{13} \leq 1
\end{aligned}
$$

$$
\begin{aligned}
& P_{i t}, I_{i t}, W_{t}, H_{t}, F_{t}, \delta_{1}^{+}, \delta_{2}^{+}, \delta_{3}^{+} \geq 0 \\
& i=1 ., 2 ., 3 \quad t=1 ., 2 ., \ldots, 6 W_{t}, H_{t}, F_{t} \text { (Integers). }
\end{aligned}
$$

\subsection{Solve the WAFGP-APP Problem}

The LINGO computer software package was used to run the Linear programming model. Table 2 presents the optimal aggregate production plan in the industrial

\begin{tabular}{|c|c|c|c|c|c|c|}
\hline Period & Product & 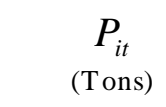 & $\begin{array}{c}I_{i t} \\
\text { (Tons) }\end{array}$ & $\begin{array}{c}W_{t} \\
(\operatorname{man})\end{array}$ & $\underset{(\operatorname{man})}{H_{t}}$ & $\begin{array}{c}F_{t} \\
\text { (man) }\end{array}$ \\
\hline 0 & $\begin{array}{ll}1 & (\mathrm{BEN}) \\
2 & (\mathrm{CAL}) \\
3 & (\mathrm{TD})\end{array}$ & $\begin{array}{l}- \\
- \\
-\end{array}$ & $\begin{array}{l}1865.25 \\
1029 \\
1860\end{array}$ & 68 & - & - \\
\hline 1 & $\begin{array}{ll}1 & (\mathrm{BEN}) \\
2 & (\mathrm{CAL}) \\
3 & (\mathrm{TD})\end{array}$ & $\begin{array}{l}0 \\
0 \\
0\end{array}$ & $\begin{array}{l}679.025 \\
900.38 \\
695.809\end{array}$ & 68 & 0 & 0 \\
\hline 2 & $\begin{array}{ll}1 & (\mathrm{BEN}) \\
2 & (\mathrm{CAL}) \\
3 & (\mathrm{TD})\end{array}$ & $\begin{array}{l}743.996 \\
0 \\
267.638\end{array}$ & $\begin{array}{l}500 \\
736.603 \\
500\end{array}$ & 68 & 0 & 0 \\
\hline 3 & $\begin{array}{ll}1 & (\mathrm{BEN}) \\
2 & (\mathrm{CAL}) \\
3 & (\mathrm{TD})\end{array}$ & $\begin{array}{l}1074.857 \\
0 \\
659.034\end{array}$ & $\begin{array}{l}691.515 \\
571.986 \\
500\end{array}$ & 68 & 0 & 0 \\
\hline 4 & $\begin{array}{ll}1 & (\mathrm{BEN}) \\
2 & (\mathrm{CAL}) \\
3 & (\mathrm{TD})\end{array}$ & $\begin{array}{l}1154.980 \\
94.019 \\
425.24\end{array}$ & $\begin{array}{l}774.505 \\
500 \\
500\end{array}$ & 68 & 0 & 0 \\
\hline 5 & $\begin{array}{ll}1 & (\mathrm{BEN}) \\
2 & (\mathrm{CAL}) \\
3 & (\mathrm{TD})\end{array}$ & $\begin{array}{l}1209.992 \\
193.317 \\
78.967\end{array}$ & $\begin{array}{l}605.228 \\
500 \\
500\end{array}$ & 68 & 0 & 0 \\
\hline 6 & $\begin{array}{ll}1 & (\mathrm{BEN}) \\
2 & (\mathrm{CAL}) \\
3 & (\mathrm{TD})\end{array}$ & $\begin{array}{l}1209.992 \\
206.662 \\
478.221\end{array}$ & $\begin{array}{l}500 \\
500 \\
500\end{array}$ & 68 & 0 & 0 \\
\hline
\end{tabular}
case study based on the current information.

Using WAFGP-APP to simultaneously minimize total production costs $\left(Z_{1}\right)$, carrying costs $\left(Z_{2}\right)$, and changes in Work force levels $\left(Z_{3}\right)$, yields total production cost of 32032504.2 DA, carrying cost of 4375292.99 DA, and changes in Work force levels of 0 . And resulting deviational value for the three fuzzy goal $\left(\mu_{1}, \mu_{2}\right.$ and $\left.\mu_{3}\right)$ are $0.9682679,0.8975380$ and 1 respectively.

Despite the good results that were obtained through the proposed model , but remains very much sensitive to the accuracy of the information and data provided by the Organization

Table 2: optimal production plan in the BENT AL firm case with WAFGP-APP model 


\section{Conclusions}

The APP is concerned with determination of production, the inventory and the workforce levels of a company on a finite time horizon. The objective is to reduce the total overall cost to fulfill a no constant demand assuming fixed sale and production capacity.

In this study we proposed an new formulation of a Weighted additive fuzzy goal programming (WAFGP) approach developed by Yaghoobi et al [22] for aggregate production planning (WAFGP-APP), The proposed model attempts to minimize total production and work force costs, carrying inventory costs and rates of changes in Work force so that in the end, the proposed models is solved by using LINGO program and getting optimal production plan.

The major limitations of the proposed model concern the assumptions made in determining each of the decision parameters, with reference to production costs, forecasted demand, maximum work force levels, and production resources. Hence, the proposed model must be modified to make it better suited to practical applications. Future researchers may also explore the fuzzy properties of decision variables, coefficients, and relevant decision parameters in APP decision problems.

\section{Acknowledgements}

The authors are grateful for the valuable comments and suggestions from the respected reviewers which have enhanced the strength and significance of our work

\section{References}

[1] Jamalnia.A., Soukhakian.M.A. A hybrid fuzzy goal programming approach with different goal priorities to aggregate production planning, Computers and Industrial Engineering. Vol 56, 2009, PP 1474-1486.

[2] Bowman.E.H. Production scheduling by the transportation method of linear programming. Operations Research, Vol 4, 1956, PP 100-103.

[3] Bowman, E. H. Consistency and optimality in managerial decision making. Management Science, Vol 9, 1963, PP 310-321.

[4] Belmokaddem.M., Mekidiche,M., Sahed.A.K. Application of a fuzzy goal programming approach with different importance and priorities to aggregate production planning. Journal of Applied Quantitative Methods. Vol 4, N3, 2009, PP 317 331.

[5] Charnes. A., Cooper.W.W. Management models and industrial applications of linear programming. New York: Wiley, 1961.
[6] Chanas. S., Kuchta. D. Fuzzy goal programming One notation. Many Meanings. Control and Cybernetics, Vol31, N4, 2002, PP 871-890.

[7] Gen, M., Tsujimura. Y., Ida, K .Method for solving Multiobjective aggregate production planning problem with fuzzy parameters. Computers and Industrial Engineering, Vol 23, 1992, PP117-120.

[8] Hannan.E.L. Linear programming with multiple fuzzy goals. Fuzzy Sets and Systems, Vol 6, 1981, PP 235-248.

[9] Hannan, E.L. On Fuzzy Goal Programming, Decision Sciences ,Vol 12, 1981,PP 522-531

[10] Holt.C.C., Modigliani F., Simon HA .Linear decision rules for production and employment scheduling. Management Science, Vol 2, 1955, PP $1-30$.

[11] Jones. C. H .Parametric production planning. Management Science, Vol 13, 1967, PP 843-866.

[12] Kim. J.S., Whang K.S . A tolerance approach to the fuzzy goal programming problems with unbalanced triangular membership function, European Journal of Operational Research, Vol 107, 1998, PP 614-624.

[13] Masud. A. S. M. Hwang, C. L. An aggregate production planning model and application of three multiple objective decision methods. International Journal of Production Research, Vol 18, 1980, PP 741-752.

[14] Narasimhan. R .Goal Programming in a Fuzzy Environment, Decision Sciences, Vol 11, 1980 ,PP 325-336

[15] Saad C. An overview of production planning model: structure classification and empirical assessment. International Journal of Production Research, Vol 20, 1982, PP 105-114.

[16] Singhal. K, Adlakha.V. Cost and shortage tradeoffs in aggregate production planning. Decision Sciences, Vol 20, 1989, PP158-165.

[17] Tang, J. Wang, D., and Fung, R. Y. K. Fuzzy formulation for multi-product aggregate production planning. Production Planning and Control, Vol 11, 2000, PP670-676.

[18] Taubert, W. H. A search decision rule for the aggregate scheduling problem. Management Science, Vol 14, 1986, PP343-359.

[19] Wang. R. C., and Fang, H. H. Aggregate production planning with multiple objectives in a fuzzy environment. European Journal of Operational Research, Vol 133, 2001, PP 521536.

[20] Wang .R.C., Liang .T.T. Aggregate production planning with multiple fuzzy goals International 
Journal of Advanced Manufacturing Technology, Vol 25, 2005, PP 589-597.

[21] Yaghoobi.M.A., Jons,D,F., Tamiz .Weighted additive models for solving fuzzy goal programming problems. Asia - Pacific Journal of Operational Research; Vol 25, N5, 2008, PP 715733.

[22] Yaghoobi.M.A., Tamiz .A method for solving fuzzy goal programming problems with based on MINMAX approach. European Journal of Operational Research, Vol 177,2007, PP 15801590.

[23] Zadeh. L. A . Fuzzy Sets. Information and Control, Vol8, 1965, PP 338-353.

[24] Zimmermann. H.-J. Description and optimization of fuzzy systems. International Journal of General Systems, Vol 2, 1976, PP 209-215.

\section{Authors' Profiles}

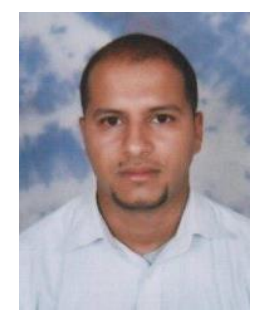

Mékidiche Mohammed is currently Assistant Professor in the faculty of economics and commerce, University of Tlemcen, Maghnia Annex, Algeria, where he teaches Statistics and econometric, Operations Research, applied microeconomics and production planning, He received the MS degree and PH.D in production and operations Management from Economics and commerce Faculty, University of Tlemcen in Algeria- .His research project is optimization in production planning, Multi Criteria Decision Making and Fuzzy Sets Theory, fuzzy goal programming, Quality control, Time series analysis and its application in forecasting, neural network and its application in management, He has published several articles in journals.

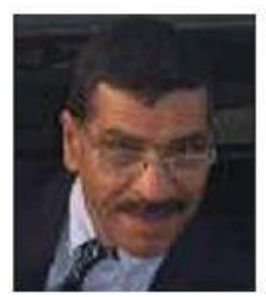

Mostefa Belmokaddem, Doctor of Economics, University professor - was graduate of the Faculty of Economics at the University of Oran in 1977 and worked as assistant lecturer and professor at the Faculty of Economics University of Tlemcen (Algeria). After receiving his Ph.D. (1982)in the Theoretical Statistics and Econo mics at the Academy of Economic Studies in Bucharest, he worked as a Lecturer at the Faculty of Economics, University of Tlemcen, Algeria, (1982-1989), Lecturer (1988-1990) and professor (1990 to present). He has participated in international scientific events and a summer school (Valencia, Spain). It presents his ideas on a wide band of key issues in microeconomics, the various techniques to aid decision making by providing useful information for each discipline and research projects. He is the author of handouts and has published several articles in journals. His research project is applied statistics and econometrics, fuzzy set, optimization, Goal programming, Multi criteria decision making.

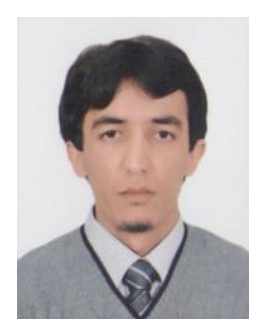

Zakaria Djemmaa is currently Assistant professor in the Faculty of Economics and Commerce, University of Tlemcen, Algeria, where he teaches statistics, decision making theory and fuzzy set theory. He holds an MSc and PHD in production and operations management from the Economics and Commerce Faculty, University of Tlemcen in Algeria. His research interests are in operations research, production management, multi criteria decision making, and scheduling and fuzzy sets theory. He has published several articles in journals.

How to cite this paper: Mohammed. Mekidiche, Mostefa Belmokaddem, Zakaria Djemmaa,"Weighted Additive Fuzzy Goal Programming Approach to Aggregate Production Planning", International Journal of Intelligent Systems and Applications(IJISA), vol.5, no.4, pp.20-29, 2013.DOI: 10.5815/ijisa.2013.04.02 